Supplement of Hydrol. Earth Syst. Sci., 24, 4189-4211, 2020

https://doi.org/10.5194/hess-24-4189-2020-supplement

(c) Author(s) 2020. This work is distributed under

the Creative Commons Attribution 4.0 License.

(c) (1)

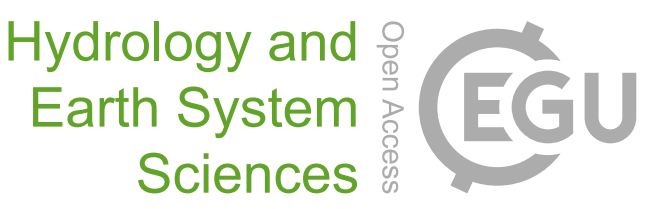

Supplement of

\title{
Data-driven estimates of evapotranspiration and its controls in the Congo Basin
}

Michael W. Burnett et al.

Correspondence to: Michael W. Burnett (mburnett@alumni.stanford.edu)

The copyright of individual parts of the supplement might differ from the CC BY 4.0 License. 
Supplemental figures
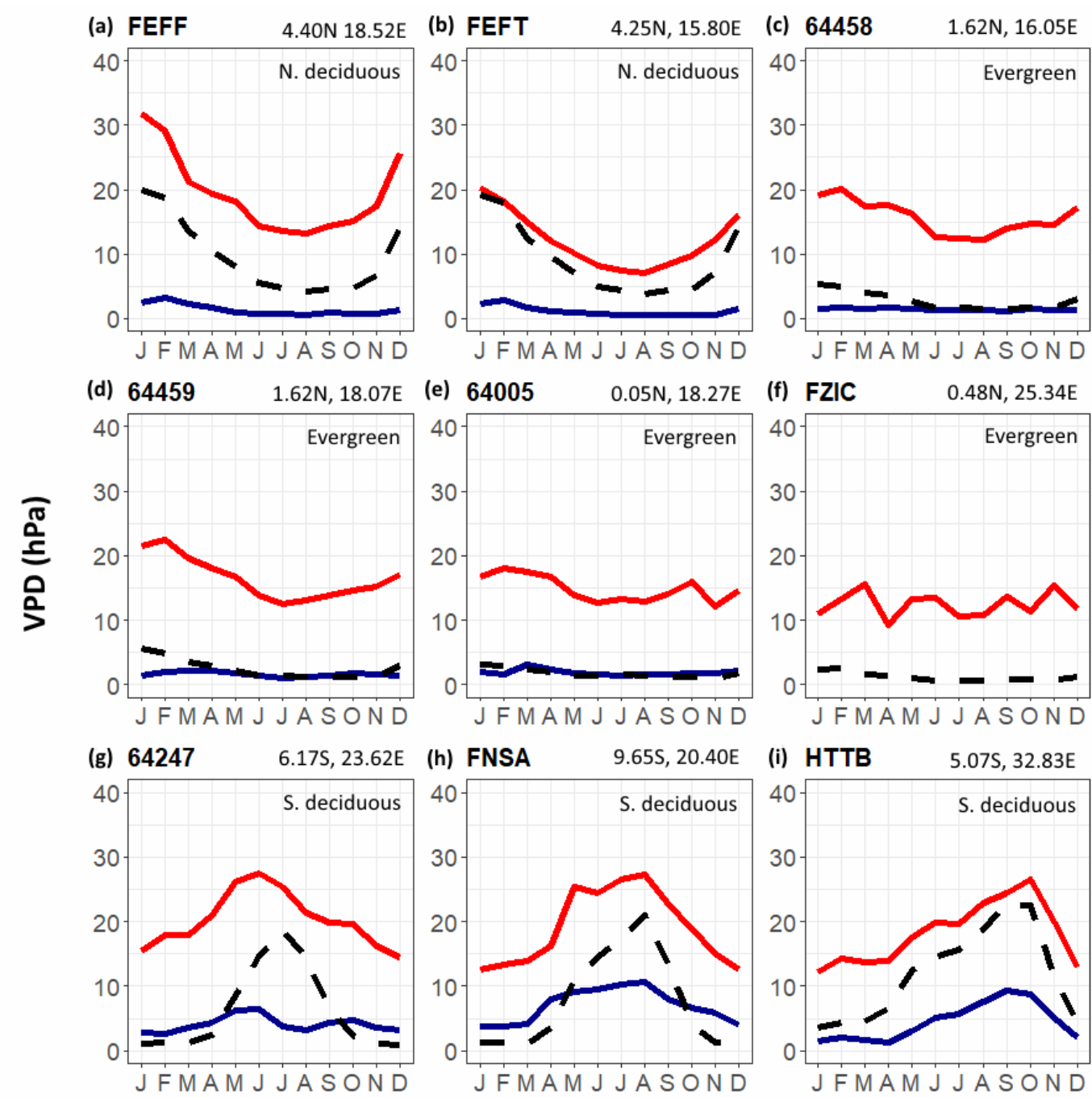

- Midday VPD - Pre-dawn VPD =- ERA-Interim mean VPD

Figure S1: Averaged hourly VPD data (hPa) from Automated Surface Observing Systems (ASOS) and Met Office Integrated Data Archive System (MIDAS) weather reports from the Congo Basin plotted alongside ERA-Interim daily VPD averages from 2002-

52016 (black dashed line). Observational VPD data are plotted as pre-dawn retrievals (blue line) and midday retrievals (red line). Panel titles reflect the International Civil Aviation Organization (ICAO) or World Meteorological Organization (WMO) location identifier for each observation station (ERA-Interim data were retrieved from the pixel within which each station is located). Latitude, longitude, and ecoregion are also provided for each panel. The observational VPD data span 2002-2016, but often with significant data gaps; only stations with at least 500 datapoints for each time of day over multiple years were included. FEFF (a) and

10 FEFT (b) are located in the area classified as northern deciduous for this study; stations 64458, 64459, 64005, and FZIC (c)-(f) are located in the equatorial rainforest region; and stations 64247, FNSA, and HTTB (g)-(i) are located in the southern deciduous ecoregion. 

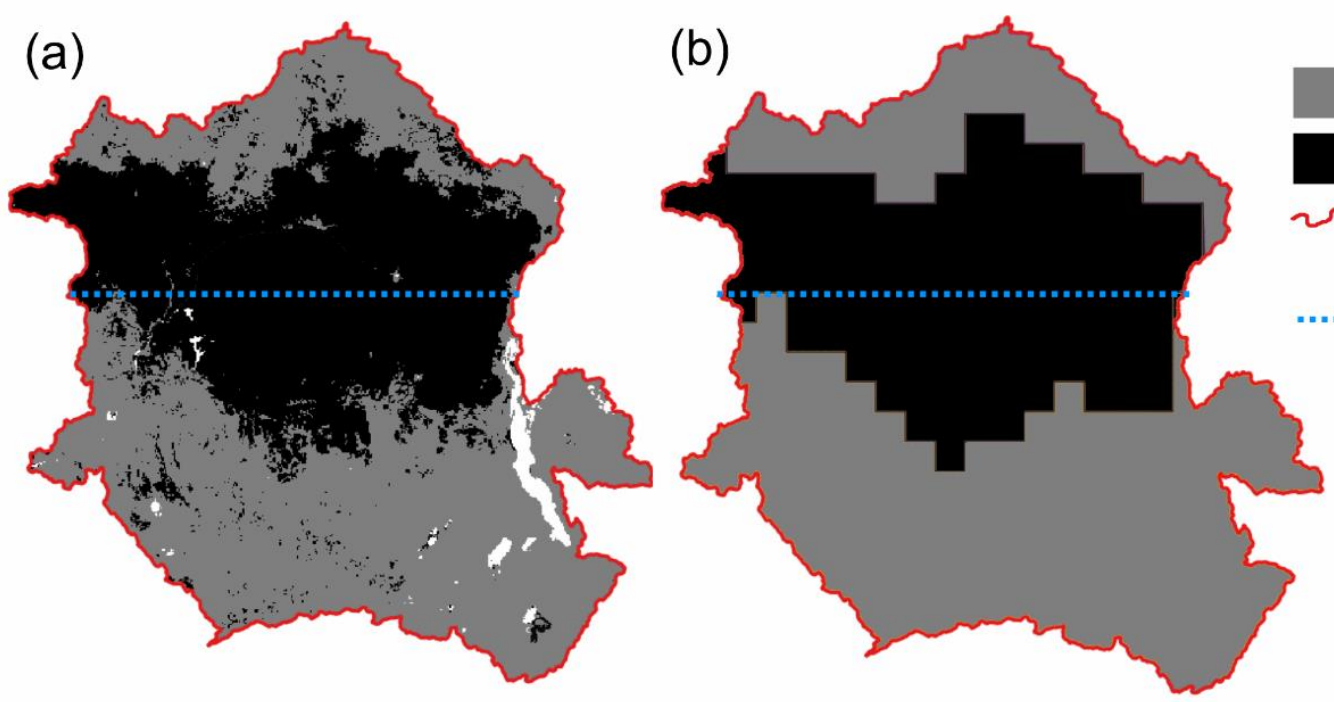

Deciduous

Evergreen

Basin boundary

... Equator

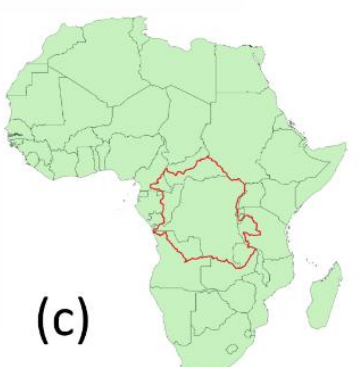

15 Figure S2: (a) MCD12C1-IGBP land cover classification, modally-averaged over the 15 study years and merged into evergreen and deciduous forest types, and (b) majority-resampled to match the coarsest spatial resolution of our other datasets $\left(1^{\circ}\right) .(\mathrm{c}) \mathrm{Context}$ of the Congo River Basin within the political boundaries of Africa.

(a) SIF monthly cycle

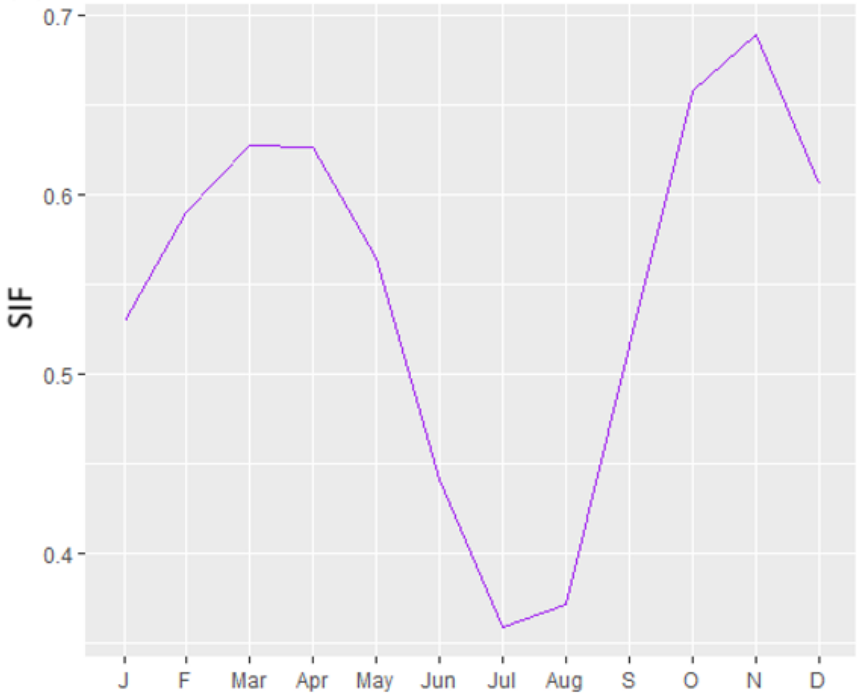

(b) SIF/PAR monthly cycle

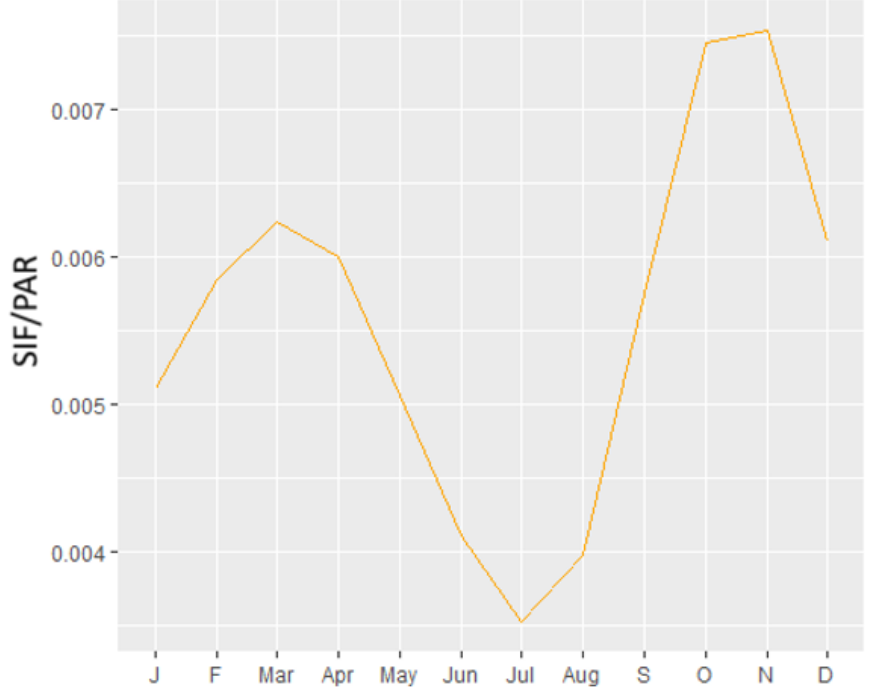

20 Figure S3: (a) GOME-2 $740 \mathrm{~nm} \mathrm{SIF,} \mathrm{presented} \mathrm{in} \mathrm{mW} \mathrm{m}^{-2} \mathrm{~nm}^{-1} \mathrm{sr}^{-1}$, averaged for each month across the entire Congo Basin, and (b) the SIF data from (a) normalized by CERES basin-average total PAR data. Note the preservation of the seasonal SIF cycle (including peak during October and November) after PAR normalization. 


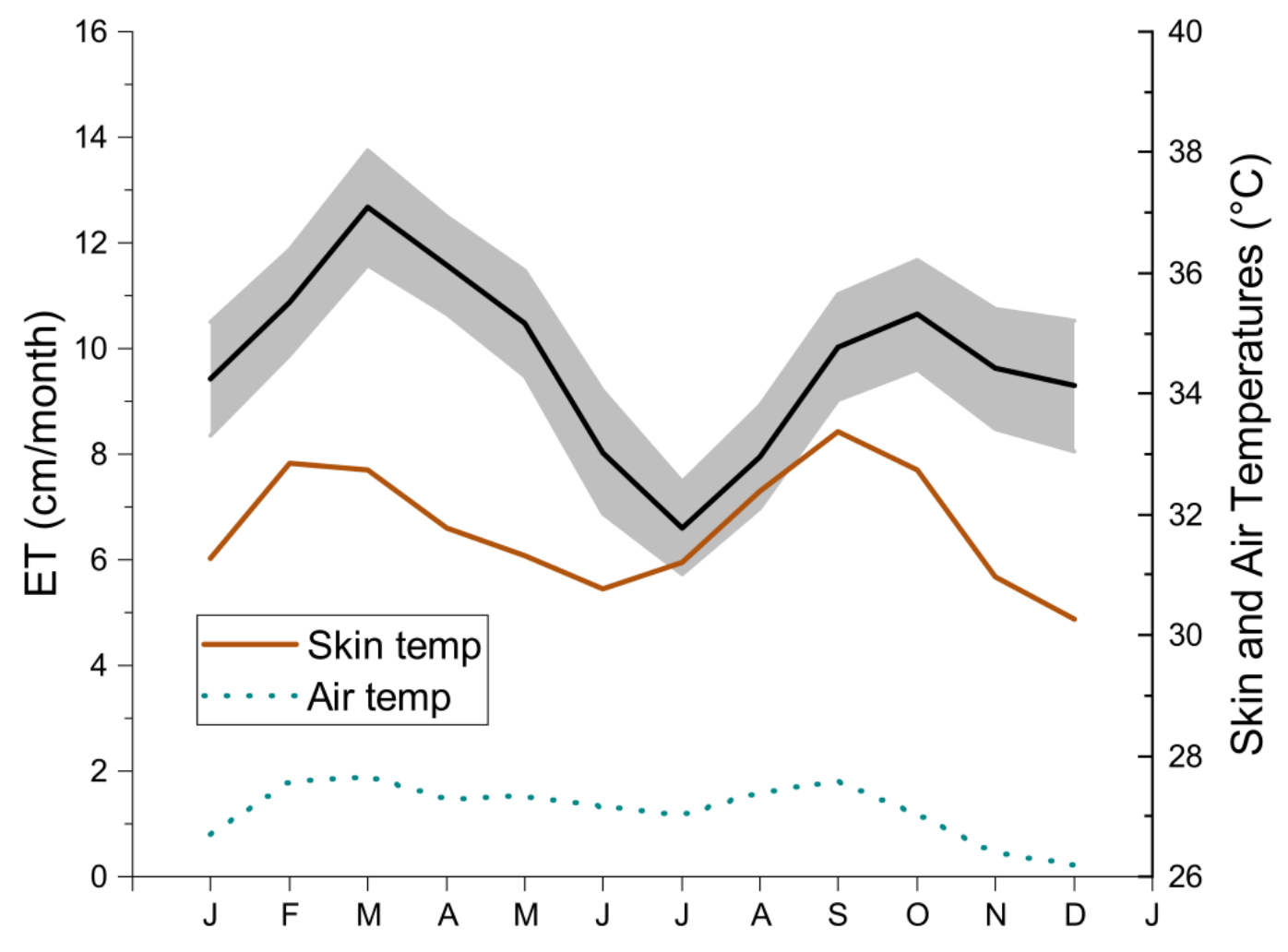

25 Figure S4: Mean monthly cycle of $E T_{w b}$ (black line with gray uncertainty range) plotted alongside those of skin temperature (brown line) and air temperature (blue dotted line) from AIRS. Data are averaged over the entire basin area. 


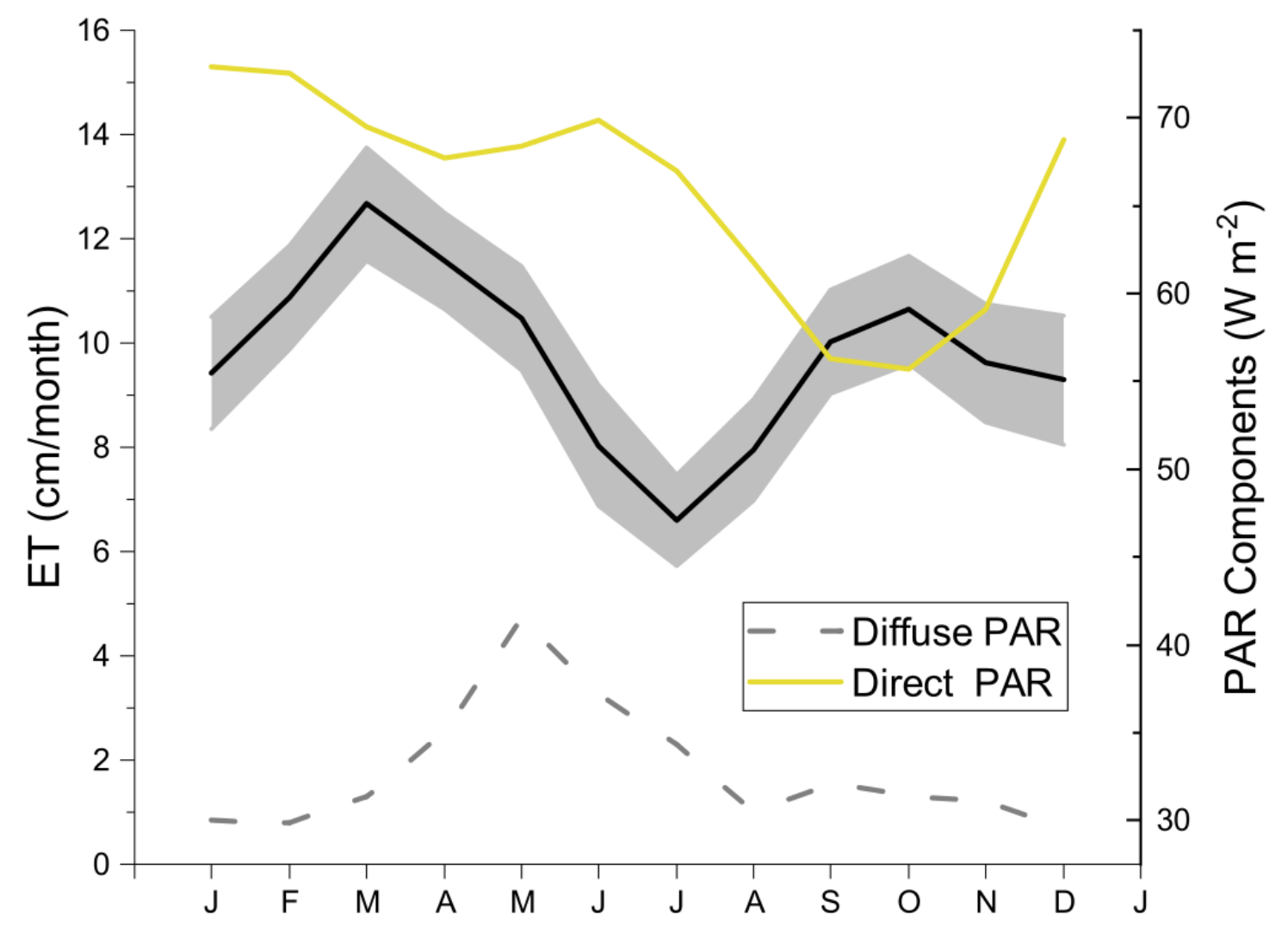

Figure S5: Mean monthly cycle of $E T_{w b}$ (black line with gray uncertainty range) plotted alongside those of PAR diff (gray dashed line) and PAR dir (yellow line) from CERES. Data are averaged over the entire basin area. 


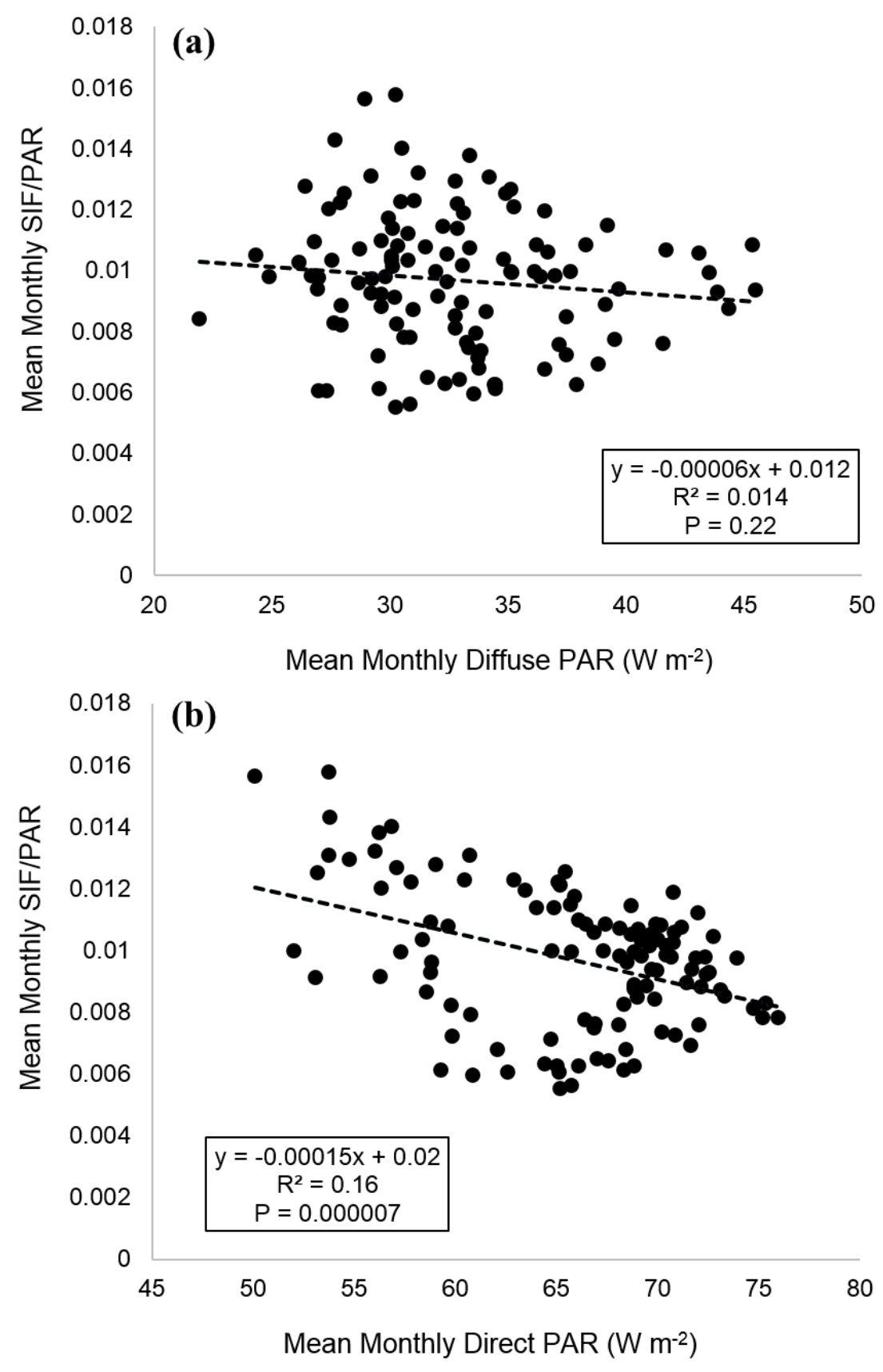

30 Figure S6: Linear regressions of monthly SIF/PAR (derived from GOME-2 and CERES) data against (a) PAR diff and (b) PAR dir from CERES. Mean seasonal cycles and long-term trends were removed. 


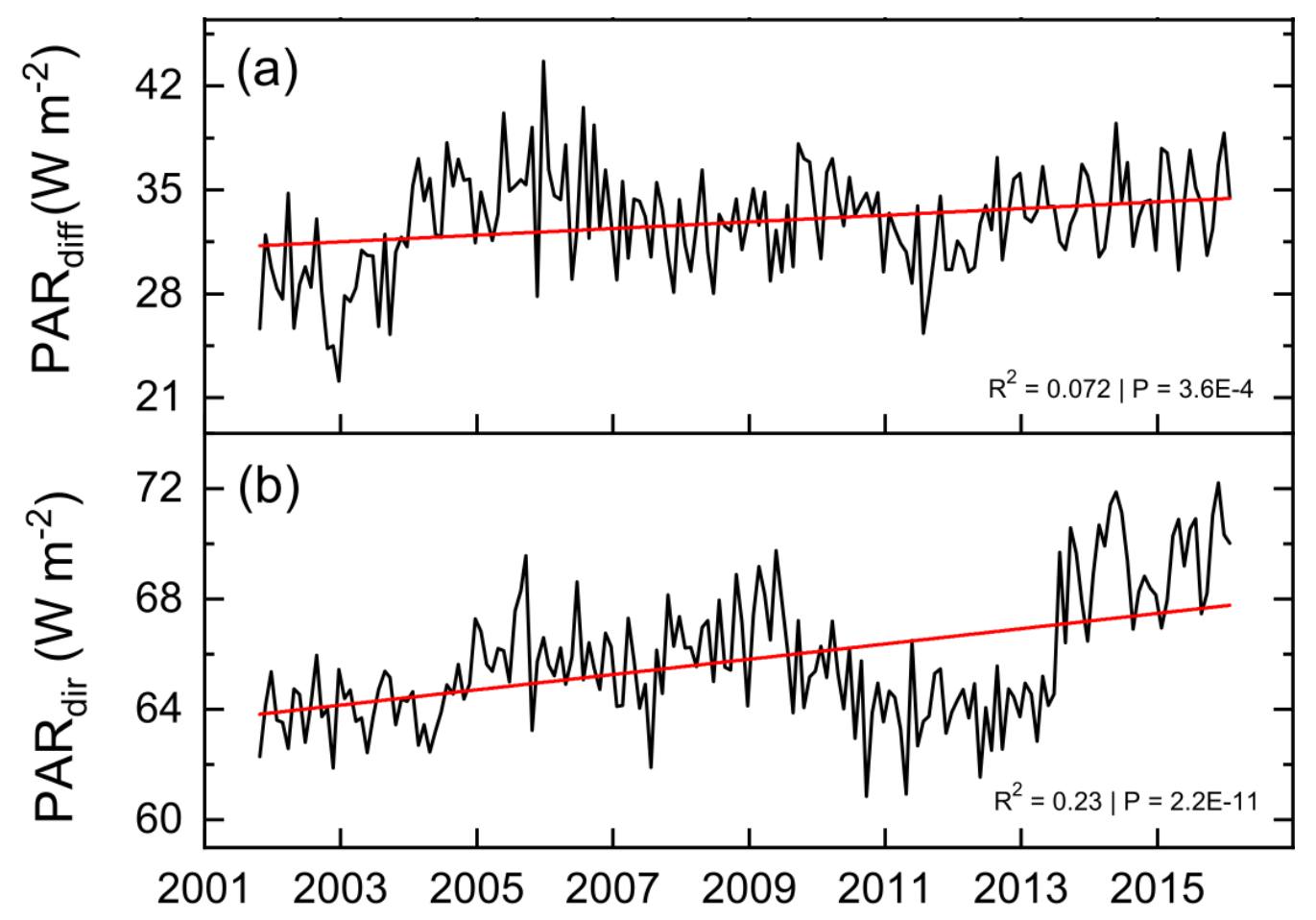

Figure S7: Linear trends from 2002-2016 of (a) PAR diff and (b) PAR dir from CERES. Average seasonal cycles were removed from the data. 